\title{
Residency and burnout: Are we so different from other training programs?
}

\author{
Amanda C. North, MD \\ Department of Urology, Montefiore Medical Center, Bronx, NY, United States
}

Cite as: North AC. Residency and burnout: Are we so different from other training programs? Can Urol Assoc J 2021;15(6Suppl1):S31-2. http://dx.doi.org/10.5489/cuaj.7228

\section{Introduction}

Burnout was first defined by Dr. Herbert Freudenberger as job dissatisfaction precipitated by work-related stress. ${ }^{1}$ It is a syndrome characterized by emotional exhaustion, depersonalization, and a decreased sense of personal achievement. The Maslach Burnout Inventory is the most commonly used tool to assess physician burnout and is a 22-item questionnaire. ${ }^{2}$ Physicians have been shown to have higher burnout rates than the general population and this is a cause for concern. ${ }^{3}$

\section{Burnout in residents}

Although burnout was first described in 1974, research examining the incidence and impact of burnout among resident physicians started appearing in the medical literature in the early 2000s. An early review article of the existing literature on burnout during medical school and residency was published in 2009 and reported burnout rates in residency ranging from $27-75 \%$, depending on the specialty. Interestingly, at the time of this review, there was no data on burnout rates among urology trainees. ${ }^{4}$

Drybye et al published a large study comparing medical students, residents/fellows, and early-career physicians in terms of burnout, symptoms of depression and suicidal ideation, quality of life, and fatigue. Resident physicians had the highest rates of burnout and fatigue, while medical students fared worst in terms of symptoms of depression and suicidal ideation. Overall, 50\% of residents reported burnout, with $37.6 \%$ reporting emotional exhaustion and $35.7 \%$ reporting depersonalization; $50.7 \%$ of residents screened positive for depression and $8.1 \%$ reported suicidal ideation in the past 12 months. Specialty-specific rates of burnout were not reported. ${ }^{5}$

The first report of burnout rates in urology residents came from Drybye et al in 2019. This study looked at burnout rates and career choice regret based on clinical specialty in post- graduate year 2 (PGY-2) residents. This study looked at a prospective cohort of 3588 second-year residents and found burnout in 45.2\% (29.6-63.8\%) and career choice regret in $14.1 \%(7.4-32.7 \%)$. Risk factors for burnout included female gender and a higher anxiety score during the fourth year of medical school. Urology was among the specialties with increased risk for burnout, with $63.8 \%$ reporting burnout; $15.5 \%$ of urology residents also reported career choice regret, however, there were only 59 urology residents included in this sample. ${ }^{6}$

The only two studies to look specifically at urology residents were published in 2019. One compared burnout rates among U.S. urology trainees to urology trainees in four European countries. Overall, 40\% of urology trainees met the criteria for burnout. European residents reported a $44 \%$ burnout rate and U.S. residents reported a 38\% burnout rate. Having more on-call weekends was associated with more burnout. Burnout was associated with worse worklife balance and more fatigue. Reading non-medical books decreased burnout. European residents reported that exercise or yoga for relaxation decreased burnout. ${ }^{7}$

The second study looked at the impact of institutional factors on burnout among U.S. urology residents; $68.2 \%$ of urology residents reported burnout. Risk factors for burnout included working more than 80 hours per week and unavailable or difficult-to-access mental health services. Protective factors included reading for relaxation, spending time with family, being part of a structured mentorship program, and having access to mental health services. ${ }^{8}$

The 2019 Urologists in Training AUA Census included the Maslach Burnout Inventory. With 415 respondents, this is the largest study of urology residents to date. The overall burnout rate was $47 \%$, with $7 \%$ scoring high for emotional exhaustion and $47 \%$ scoring high for depersonalization. Interestingly, there were significant differences in burnout based on training level. PGY-2 urology residents reported the highest burnout rates at $65.2 \%$, while chief residents had the lowest burnout rates at $40 \%$. When asked about career choice regret, $84.6 \%$ of residents would choose medicine again. Of those who would choose medicine again, 95.9\% would choose urology. Like the burnout data, PGY-2 resi- 
dents were most likely to express career choice regret, with $28.3 \%$ revisiting their career choice. ${ }^{9}$

Table 1 summarizes resident burnout rates in the most recently published studies.

\section{Conclusions}

Data on burnout rates among urology residents show burnout rates ranging from $38-68.2 \%$. The largest study to date suggests the burnout rate is around $47 \%$, which is consistent with burnout data from other specialties. One difficulty with evaluating multispecialty studies that include urology residents is that the burnout data seems to depend on the year of training, with PGY-2 urology residents consistently showing much higher burnout rates than other training years. This may reflect the hierarchical nature of surgical training, with junior residents being assigned less meaningful tasks and taking more nights on-call, while senior residents have more autonomy. There appears to be some correlation with institutional factors where training programs not adhering to American College of Graduate Medical Education (ACGME) guidelines regarding work hours and access to mental health services tend to have residents with higher burnout rates.

Further study on burnout among urology trainees is clearly warranted to better understand the causes and prevention of burnout in our future workforce. It is imperative that residency programs adhere to all ACGME guidelines regarding resident well-being. Training programs need to focus resources on the PGY-2 residents in particular, as they are suffering the most. Our professional organizations could provide online educational modules about preventing, identifying, and treating physician burnout. The American Medical Association has created content in their AMA STEPS Forward program, with 12 modules specifically addressing physician burnout and well-being. ${ }^{10}$ Both the American Urological Association and the Canadian

\begin{tabular}{lcc}
\hline \multicolumn{3}{l}{ Table 1. Published burnout rates among urology residents } \\
\hline Source & No. of respondents & Burnout rate \\
\hline Drybye et $\mathrm{al}^{6}$ (2019) & 59 & $63.8 \%$ \\
Marchalik et $\mathrm{al}^{7}$ (2019) & 369 & $40.0 \%$ \\
${\text { Marchalik et } \mathrm{al}^{8} \text { (2019) }}_{\text {AUA census }}{ }^{(2019)}$ & 211 & $68.2 \%$ \\
\hline
\end{tabular}

Urological Association could provide urologist-specific content for use in resident education. It is our responsibility to help prevent burnout among our trainees.

\section{References}

1. Freudenberger HJ. Staff burnout. I Soc Issues 1974;30:159-65. https://doi. org/10.1111/i.1540-4560.1974.tb00706.x

2. Maslach C. Burnout: A multidimensional perspective. In: Schaufeli WB, Maslach C, Marek T, eds. Professional Burnout: Recent Developments in Theory and Research. Washington, DC: Taylor \& Francis; 1993

3. Shanafelt TD, Boone S, Tan $L$, et al. Burnout and satisfaction with work-life balance among US physicians relative to the general US population. Arch Intern Med 2012;172:1377-85. https://doi.org/10.1001/archinternmed.2012.3199

4. IsHak WW, Lededer $S$, Mandili C, et al. Burnout during residency training: a literature review. I Grad Med Ed 2009:236-42. https://doi.org/10.4300/JGME-D-09-00054.1

5. Drybye LN, West CP, Satele D, et al. Burnout among U.S. medical students, residents, and early career physicians relative to the general U.S. population. Acad Med 2014;89:443-51. https://doi.org/10.1097/ACM.0000000000000134

6. Dyrbye LN, Burke SE, Hardeman RR, et al. Association of clinical specialty with symptoms of burnout and career choice regret among U.S. resident physicians. JAMA 2018;320:1114-30. https://doi.org/10.1001/jama.2018.12615

7. Marchalik D, Goldman CC, Carvalho FFL, et al. Resident burnout in U.S. and European urology residents: An international concern. BJU Int 2019:124:349-56. https://doi.org/10.1111/bju.14774

8. Marchalik D, Brems J, Rodriguez A, et al. The impact of institutional factors on physician burnout: A national study of urology trainees. Urology 2019;131:27-35. https://doi.org/10.1016/i.uroogy.2019.04.042

9. AUA. Census results: U.S. urologists. Available at: https://www.auanet.org/research/researchresources/aua-census/census-results. Accessed Feb. 12, 2021

10. AMA Ed Hub. Available at: https://edhub.ama-assn.org/steps-forward. Accessed Feb. 12, 2021

Correspondence: Dr. Amanda C. North, Department of Urology, Montefiore Medical Center, Bronx, NY, United States; anorth@montefiore.org 